\title{
The Rating Model of Ukraine's Regions According to the Level of Economic Development
}

\author{
P.M. Hryhoruk ${ }^{1}$, N.A. Khrushch ${ }^{2}$, S.S. Grygoruk ${ }^{3}$ \\ ${ }^{1}$ Department of Automated Systems and Modeling in Economics, Khmelnytskyi National University, 11 Instytutska str, \\ Khmelnytskyi, Ukraine \\ ${ }^{2}$ Department of Finance, Banking and Insurance, Khmelnytskyi National University, 11 Instytutska str, Khmelnytskyi, Ukraine, \\ ${ }^{3}$ Department of Software Engineering, Khmelnytskyi National University, 11 Instytutska str, Khmelnytskyi, Ukraine,
}

\section{Article Info}

Received Mar 18, 2019

Keyword:
Level of economic
development
Evaluation
Comprehensive index
Additive and multiplicative
$\quad$ convolutions
Grouping
Clustering

\begin{abstract}
The identification of the real level of economic development of the region is an important condition to design effective regional development policy. Economic development is characterized by a large number of indicators. This study provides an approach for assessing the level of economic development based on the use of a comprehensive index, which is a convolution of initial indicators. The model involves the use of both a group of absolute indicators and a group of relative measures of dynamics. Each of the groups of indicators has its special data normalization procedure and its special method of convolution into a partial comprehensive index. The outcome of the evaluation is obtained by weighted multiplicative convolution of partial comprehensive indexes. In this study, the level of economic development of regions of Ukraine according to the data of 2017 has evaluated. As a result, Ukraine's regions were allocated into three groups: with the level of economic development above average, with the average level of economic development and with the level of development below average. The article suggests a way to determine the boundary values of the comprehensive index for grouping. Comparison of the obtained results of grouping with the results of clustering of the Ukraine's regions by the k-means method with the same data showed their identity. The article shows that Ukraine's regions can be allocated by the level of economic development into other number of groups.
\end{abstract}

\section{Corresponding Author:}

P.M. Hryhoruk, Department of Automated Systems and Modeling in Economics, Khmelnytskyi National University, 11 Instytutska str, Khmelnytskyi,29016, Ukraine.

Email: violete@ukr.net

\section{Introduction}

Currently, Ukraine and its regions are facing new challenges, which are formed under the influence of the growth of openness of the global economy, increasing uncertainty of directions and rates of such growth. This requires significant changes in the strategic vision of the development of the Ukraine's regions and the identification of the objectives of the state regional policy. A clear understanding of the asymmetric nature of regional development should guide regional policy to address the challenges of ensuring equal opportunities for economic activity for the population and business, as well as equal access to key social, administrative and other services that provide opportunities for self-realization. Strategic regional development planning is an important tool of state regulation, which helps to maintain the necessary economic proportions, ensures coordinated purposeful functioning of all parts of the economic system. For the Ukraine's economy, strategic planning is especially important, because it allows predicting the processes of development and privatization, 
demonopolization, technical renewal of production. The State Strategy for Regional Development for the period up to 2020 [1] defines the goals of the state regional policy. One of the most important goals is to increase the level of competitiveness of regions through the qualitative use of endogenous factors to ensure their dynamic economic growth. Strategic planning is the organizational center of strategic management, on the basis of which the necessary preconditions are formed and decisions are taken directed to the practical implementation of the socio-economic transformation of the region. In developing an effective development policy one of the most important conditions is the identification of the actual level of region's economic development. This problem may be solved if different factors influencing regional development are taken into consideration. The assessment of actual state of regional economic development derives from the quantitative analysis of regional disparities. This leads to the use of tools of economic and mathematical modeling.

The approaches of the researches to the measurement of the level of region's economic development and assessment of regional disparities are not uniformed. At present, there are many different approaches to solving such problems. Regional economic inequalities can be measured, inter alia, by a variety of indices based on the indicator of Gross Regional Product (GRP), like coefficient of variation and Hoover Concentration Index, the Theil index, the Herfindahl index, the Geographic concentration index [2]. At the same time, both economic and environmental indicators can be used [3]. A combination of different indicators can be implemented through the use of Structural Equation Modeling [4]. To analyze development gaps in the study of development economics we can use Klassen Typology theory. It is based on comparing the level of GRP for the current year with the previous year's [5], [6]. Using this approach allows to gradate the level of development by four quadrants by comparing the average value of the growth rate and the average contribution of each sector development. As noted in [5], using Klassen typology, it is possible to describe the growth pattern of the region's economic development by comparing data from the current year with the previous year or some other base year. One of the most used approaches in the researches directed to the assessment of regional development, including economic, is the use of the method of comprehensive index [7], [8], [9], [10], [11], [12], [13], [14]. It is based on the calculation of a comprehensive or composite index, which accumulates all the information contained in the initial set of indicators. This approach makes it possible to move from a multidimensional description of the economic development of regions to a onedimensional one. This simplifies their further comparison and ranking, identifying the pattern of regions, the degree of their compliance with some imaginary "ideal" and the definition of strategic measures to improve the situation.

In addition, the comprehensive index includes all the influence of the indicators and coefficients selected in the study, it also reduces the assessing the level of economic development to one quantitative value, which helps to determine the imbalances and greatly facilitates the economic interpretation of the outcomes.

Assessment of economic development of a separate region of the country may be based on the identification of homogeneous aggregates of regions described by the set of economic indicators. In the case of a large number of indicators, it is expedient to use the methods of machine learning and data analysis [15]. In particular, cluster analysis is an effective method that allows to group regions into homogeneous sets using a wide range of indicators. Thus, it also allows to take into account the multidimensionality of the description of the economic development of the regions. The application of clustering methods to solve the problems of determining the economic development level of regions is shown in [6], [16], [17], [18], [19].

In this paper, we propose a method of rating the regions based on the use of a comprehensive index.

\section{Materials and methods}

In most cases, design of a comprehensive index is based on the requirement of representing all the initial indicators as incentives. In this case, a positive correlation is maintained with the quality to be investigated. In addition, the value of the comprehensive index should not depend on initial indicators' units of measurement. In order to comply with these requirements, it is necessary to unify the scales on which the initial indicators are measured. Typically, a comprehensive index is designed in such a way that its value is within the range from 0 to 1 . This improves the meaningful interpretation of its values and allows to compare various objects. The transformation of the initial indicators is carried out according to the (1).

$$
u_{i j}=1-\frac{\left|x_{i j}-x_{j}^{*}\right|}{x_{j \max }-x_{j \min }}
$$


where $u_{i j}$ are normalized values of indicators, $x_{i j}$ - initial values of indicators, $x_{j \min }=\min _{i} x_{i j}, x_{j \max }=\max _{i} x_{i j}$ ,$x_{j}^{*}=\left\{\begin{array}{ll}x_{j \max }, & \text { when } X_{j} \text { is a incentive; } \\ x_{j \min }, & \text { when } X_{j} \text { is a disincentive; }\end{array}, i=1 . . m, j=1 . . n, m-\right.$ number of researched units (regions), $n-$ number of initial indicators.

In the case where initial indicators are the relative measures of dynamics, like growth rates, it is expedient to make the transformation according to the (2).

$$
u_{i j}= \begin{cases}\frac{x_{i j}}{x_{j \max }}, & \text { when } X_{j} \text { is a incentive; } \\ \frac{x_{j \min }}{x_{i j}}, & \text { when } X_{j} \text { is a disincentive; }\end{cases}
$$

Procedure of data normalization may has another type, depending on the nature of the indicator and its dynamics.

The formation of the synthesizing function $Q$, which determines the value of the comprehensive index, is carried out by using linear additive or multiplicative convolution in accordance with (3) and (4).

$$
\begin{aligned}
& Q_{A i}=\sum_{j=1}^{n} w_{j} u_{i j} \\
& Q_{M i}=\prod_{j=1}^{n} u_{i j}^{w_{j}}
\end{aligned}
$$

Where $Q_{A i}, Q_{M i}$ are values of the comprehensive index calculated by linear additive or multiplicative convolution respectively, $w_{j}$ - weight coefficients of normalized initial indicators, $j=1 . . n, i=1 . . m$.

Weight coefficients should meet the (5).

$$
\sum_{j=1}^{n} w_{j}=1
$$

In this case, values of the comprehensive index also will be between 0 and 1 .

It should be noted that the small number of initial indicators can lead to loss of informativeness of outcomes, but excessive their number - to reduction of influence of each indicator on outcomes and decrease of the differentiating property of the comprehensive index.

There are currently no formal rules for giving an advantage to additive or multiplicative convolution. However, if the initial values are absolute values, then in our opinion, it is expedient to use additive convolution, and if the initial values are relative measures of dynamics, then it is better to use multiplicative convolution. In the case, when among the selected indicators there are both absolute and relative, we propose to use block convolution according to the (6).

$$
Q_{i}=\alpha_{A} Q_{A i} \cdot \alpha_{M} Q_{M i}
$$

Where $Q_{i}$ is a final value of comprehensive index, $Q_{A i}$ - value of partial comprehensive index calculated by the formula like (3) for the initial indicators measured on absolute scale, $Q_{M i}$-value of partial comprehensive index calculated by the formula like (4) for the initial indicators, that are relative measures of dynamics, $\alpha_{A}$, $\alpha_{M}$ - weight coefficients of partial comprehensive indexes.

The choice of the set of initial indicators to assess the level of economic development is a difficult task because a large number of indicators complicate the procedure of evaluation and interpretation of outcomes, but a small number leads to loss of information and makes the findings less reliable. 
The most important economic indicator is GRP and other indicators related to it: GRP per capita, volume index of GRP in prices of the previous year, and others. They are integrated indicators of region's economic development which characterize the impact of the region to the forming the Gross Domestic Product.

Analysis of scholarly papers in this field [7], [9], [11], [14], [20], [21] and authors' own studies allow to conclude that the level of the economic development of the region is also characterized by the indicators of the industry structure, financial and investment indicators, employment indicators and many others. Significant role is played by export indicators, since they reflect the specialization of the region, it international integration and cooperation. This has contributed to the identification of a system of indicators for the practical implementation of the proposed approach to assessing the level of economic development of the regions of Ukraine and their grouping.

\section{Results and discussion}

Consider rating of regions of Ukraine for indicators of economic development based on the integral indicator. We choose the 2017 as the base period. As initial indicators we will choose the following: $X_{1}$-capital investment, mil. UAH; $X_{2}$ - export_volume, mil. USD; $X_{3}$ - employment rate, $\% ; X_{4}$ - unemployment rate after the methodology of ILO, $\% ; X_{5}-$ volume index of GRP in prices of the previous year, $\% ; X_{6}$ - industrial output index, $\%$ to the previous year; $X_{7}$ - agriculture output index, $\%$ to the previous year.

It should be noted that first four indicators are measured in absolute scale and we normalize them by the (1). Indicators $X_{5}-X_{7}$ are relative measures of dynamics, therefore we use formula like (2) to normalize them. Also, we take into account fact that indicator $X_{4}$ is disincentive, and other indicators are incentives.

The information base for calculations is data of State Statistics Service of Ukraine [22], [23]. Initial data for calculation is presented in Table 1, and normalized indicator's values resulted in Table 2.

Table 1. Values of the initial indicators

\begin{tabular}{clccccccc}
\hline Code & \multicolumn{1}{c}{ Region } & $X_{1}$ & $X_{2}$ & $X_{3}$ & $X_{4}$ & $X_{5}$ & $X_{6}$ & $X_{7}$ \\
\hline C_1 & Vinnytsia & 11744 & 1217.7 & 55.3 & 10.7 & 101.2 & 108.2 & 95.8 \\
C_2 & Volyn & 7042 & 689.3 & 48.8 & 12.5 & 103.3 & 105.7 & 104.8 \\
C_3 & Dnipro & 42908 & 7052.8 & 58.0 & 8.5 & 103.1 & 100.1 & 100.5 \\
C_4 & Donetsk & 17269 & 4432.6 & 49.4 & 14.6 & 92.5 & 89.1 & 102.2 \\
C_5 & Zhytomyr & 7722 & 589.7 & 56.4 & 10.8 & 102.7 & 109.5 & 105.8 \\
C_6 & Zakarpattia & 5624 & 1446.4 & 53.8 & 10.5 & 99.4 & 100.3 & 101.4 \\
C_7 & Zaporizhzhia & 15880 & 2980.9 & 55.2 & 10.7 & 104.7 & 106.2 & 96.7 \\
C_8 & Ivano-Frankivsk & 9708 & 665.4 & 55.0 & 8.5 & 106.3 & 112.0 & 104.0 \\
C_9 & Kyiv & 34494 & 1748.4 & 58.0 & 6.5 & 105.2 & 110.3 & 95.7 \\
C_10 & Kyrovohrad & 7321 & 415.6 & 53.3 & 12.2 & 95.2 & 105.5 & 86.1 \\
C_11 & Luhansk & 3330 & 233.9 & 54.7 & 16.6 & 86.4 & 69.0 & 94.0 \\
C_12 & Lviv & 24106 & 1585.2 & 56.2 & 7.5 & 101.5 & 106.0 & 106.1 \\
C_13 & Mykolaiv & 11178 & 1900.6 & 56.8 & 10.3 & 98.6 & 101.5 & 90.9 \\
C_14 & Odesa & 22300 & 1813.9 & 56.1 & 7.3 & 106.6 & 112.2 & 99.4 \\
C_15 & Poltava & 15855 & 1864.5 & 54.0 & 12.0 & 95.8 & 98.9 & 83.2 \\
C_16 & Rivne & 6127 & 383.3 & 55.1 & 11.6 & 100.5 & 109.3 & 105.0 \\
C_17 & Sumy & 6947 & 672.7 & 57.4 & 9.1 & 103.7 & 101.7 & 100.0 \\
C_18 & Ternopil & 7151 & 380.2 & 51.0 & 11.9 & 103.6 & 108.5 & 111.1 \\
C_19 & Kharkiv & 19362 & 1191.5 & 60.6 & 6.1 & 99.8 & 106.1 & 90.1 \\
C_20 & Kherson & 7362 & 289.2 & 56.2 & 11.1 & 100.5 & 103.2 & 99.6 \\
C_21 & Khmelnytskyi & 10500 & 467.6 & 54.7 & 8.9 & 109.0 & 101.6 & 112.0 \\
C_22 & Cherkasy & 8144 & 617.8 & 56.7 & 10.2 & 98.0 & 99.1 & 88.5 \\
C_23 & Chernivtsi & 2992 & 149.8 & 56.6 & 8.4 & 100.3 & 106.7 & 105.3 \\
C_24 & Chernihiv & 7351 & 625.1 & 56.1 & 11.2 & 99.7 & 96.5 & 105.3 \\
\hline & & & & & & & & \\
\hline
\end{tabular}


For the first five indicators, we calculate the partial comprehensive index by the (3), and for the last three indicators - by the (4). Since we don't have any information about the importance of the initial indicators and their priority, we will consider them to be equivalent. Therefore, the weight coefficients will be the same. Accordingly, for the first group of indicators $w_{j}=1 / 4, j=1 . .4$; for the second group $w_{j}=1 / 3, j=1 . .3$. The resulting values of the comprehensive index of economic development are calculated by the (6), also considering the value of partial indexes to be equal: $\alpha_{A}=\alpha_{M}=1 / 2$. The values of the partial comprehensive indicators and the values of resulting comprehensive index will also be recorded in Table 2.

Table 2. Normalized values of indicators and results of the comprehensive evaluation

\begin{tabular}{ccccccccccc}
\hline Code & $U_{1}$ & $U_{2}$ & $U_{3}$ & $U_{4}$ & $U_{5}$ & $U_{6}$ & $U_{7}$ & $Q_{A}$ & $Q_{M}$ & $Q$ \\
\hline C_1 & 0.22 & 0.15 & 0.55 & 0.56 & 0.93 & 0.96 & 0.86 & 0.372 & 0.915 & 0.583 \\
C_2 & 0.10 & 0.08 & 0.00 & 0.39 & 0.95 & 0.94 & 0.94 & 0.143 & 0.942 & 0.366 \\
C_3 & 1.00 & 1.00 & 0.78 & 0.77 & 0.95 & 0.89 & 0.90 & 0.888 & 0.911 & 0.900 \\
C_4 & 0.36 & 0.62 & 0.05 & 0.19 & 0.85 & 0.79 & 0.91 & 0.305 & 0.850 & 0.509 \\
C_5 & 0.12 & 0.06 & 0.64 & 0.55 & 0.94 & 0.98 & 0.94 & 0.345 & 0.954 & 0.573 \\
C_6 & 0.07 & 0.19 & 0.42 & 0.58 & 0.91 & 0.89 & 0.91 & 0.315 & 0.904 & 0.533 \\
C_7 & 0.32 & 0.41 & 0.54 & 0.56 & 0.96 & 0.95 & 0.86 & 0.459 & 0.922 & 0.651 \\
C_8 & 0.17 & 0.07 & 0.53 & 0.77 & 0.98 & 1.00 & 0.93 & 0.385 & 0.967 & 0.610 \\
C_9 & 0.79 & 0.23 & 0.78 & 0.96 & 0.97 & 0.98 & 0.85 & 0.691 & 0.932 & 0.802 \\
C_10 & 0.11 & 0.04 & 0.38 & 0.42 & 0.87 & 0.94 & 0.77 & 0.237 & 0.858 & 0.451 \\
C_11 & 0.01 & 0.01 & 0.50 & 0.00 & 0.79 & 0.61 & 0.84 & 0.130 & 0.742 & 0.311 \\
C_12 & 0.53 & 0.21 & 0.63 & 0.87 & 0.93 & 0.94 & 0.95 & 0.558 & 0.941 & 0.724 \\
C_13 & 0.21 & 0.25 & 0.68 & 0.60 & 0.90 & 0.90 & 0.81 & 0.434 & 0.872 & 0.615 \\
C_14 & 0.48 & 0.24 & 0.62 & 0.89 & 0.98 & 1.00 & 0.89 & 0.557 & 0.954 & 0.729 \\
C_15 & 0.32 & 0.25 & 0.44 & 0.44 & 0.88 & 0.88 & 0.74 & 0.362 & 0.832 & 0.549 \\
C_16 & 0.08 & 0.03 & 0.53 & 0.48 & 0.92 & 0.97 & 0.94 & 0.281 & 0.944 & 0.515 \\
C_17 & 0.10 & 0.08 & 0.73 & 0.71 & 0.95 & 0.91 & 0.89 & 0.404 & 0.917 & 0.609 \\
C_18 & 0.10 & 0.03 & 0.19 & 0.45 & 0.95 & 0.97 & 0.99 & 0.193 & 0.970 & 0.433 \\
C_19 & 0.41 & 0.15 & 1.00 & 1.00 & 0.92 & 0.95 & 0.80 & 0.640 & 0.886 & 0.753 \\
C_20 & 0.11 & 0.02 & 0.63 & 0.52 & 0.92 & 0.92 & 0.89 & 0.320 & 0.910 & 0.540 \\
C_21 & 0.19 & 0.05 & 0.50 & 0.73 & 1.00 & 0.91 & 1.00 & 0.367 & 0.967 & 0.596 \\
C_22 & 0.13 & 0.07 & 0.67 & 0.61 & 0.90 & 0.88 & 0.79 & 0.369 & 0.856 & 0.562 \\
C_23 & 0.00 & 0.00 & 0.66 & 0.78 & 0.92 & 0.95 & 0.94 & 0.360 & 0.937 & 0.581 \\
C_24 & 0.11 & 0.07 & 0.62 & 0.51 & 0.91 & 0.86 & 0.94 & 0.328 & 0.904 & 0.544 \\
\hline & & & & & & & & & &
\end{tabular}

Next we make a ranking the Ukraine's regions according to the values of the calculated comprehensive index. Results of the ranking are presented in Table 3. Based on the results of the ranking, we allocate the regions of Ukraine into three groups: the first group - regions with a level of economic development above the average value, the second group - the regions with an average level of economic development, and the third group regions with a level of economic development below the average value. To determine the bounders of such allocation we consider values $\delta_{j}=\mathrm{Q}_{\mathrm{j}} / \mathrm{Q}_{j-1}$, where $j$ is a rank of the region, $j=2 \ldots n$. Those values of $j$, in which the value of $\delta_{j}$ differs substantially from the previous one, will be considered as limit value for each group of regions. In this case we can emphasize values $\delta_{6}=0.90$ and $\delta_{21}=0.89$, that have property pointed above. So, groups are following.

So, groups have such view:

first group contains Dnipro, Kyiv, Kharkiv, Odesa and Lviv regions;

second group consists of Zaporizhzhia, Mykolaiv, Ivano-Frankivsk, Sumy, Khmelnytskyi, Vinnitsa, Chernivtsi, Zhytomyr, Cherkassy, Poltava, Chernihiv, Kherson, Zakarpattia, Rivne and Donetsk regions; third group contains Kyrovohrad, Ternopil, Volyn and Luhansk regions. 
To verify the correctness of the obtained result, we will conduct a clustering the regions of Ukraine according to a selected set of indicators. To do this we will use the k-means method selected the number of clusters equal to three. The clustering results obtained with the software "Statistica" are shown in Fig. 1.

Table 3. Ranking of the Ukraine's regions by the values of the comprehensive index

\begin{tabular}{clccc}
\hline Code & Region & $Q$ & Region's rank & $\delta$ \\
\hline C_3 & Dnipro & 0.900 & 1 & - \\
C_9 & Kyiv & 0.802 & 2 & 0.89 \\
C_19 & Kharkiv & 0.753 & 3 & 0.94 \\
C_14 & Odesa & 0.729 & 4 & 0.97 \\
C_12 & Lviv & 0.724 & 5 & 0.99 \\
C_7 & Zaporizhzhia & 0.651 & 6 & 0.90 \\
C_13 & Mykolaiv & 0.615 & 7 & 0.95 \\
C_8 & Ivano-Frankivsk & 0.610 & 8 & 0.99 \\
C_17 & Sumy & 0.609 & 9 & 1.00 \\
C_21 & Khmelnytskyi & 0.596 & 10 & 0.98 \\
C_1 & Vinnytsia & 0.583 & 11 & 0.98 \\
C_23 & Chernivtsi & 0.581 & 12 & 1.00 \\
C_5 & Zhytomyr & 0.573 & 13 & 0.99 \\
C_22 & Cherkassy & 0.562 & 14 & 0.98 \\
C_15 & Poltava & 0.549 & 15 & 0.98 \\
C_24 & Chernihiv & 0.544 & 16 & 0.99 \\
C_20 & Kherson & 0.540 & 17 & 0.99 \\
C_6 & Zakarpattia & 0.533 & 18 & 0.99 \\
C_16 & Rivne & 0.515 & 19 & 0.97 \\
C_4 & Donetsk & 0.509 & 20 & 0.99 \\
C_10 & Kyrovohrad & 0.451 & 21 & 0.89 \\
C_18 & Ternopil & 0.433 & 22 & 0.96 \\
C_2 & Volyn & 0.366 & 23 & 0.85 \\
C_11 & Luhansk & 0.311 & 24 & 0.85 \\
\hline
\end{tabular}

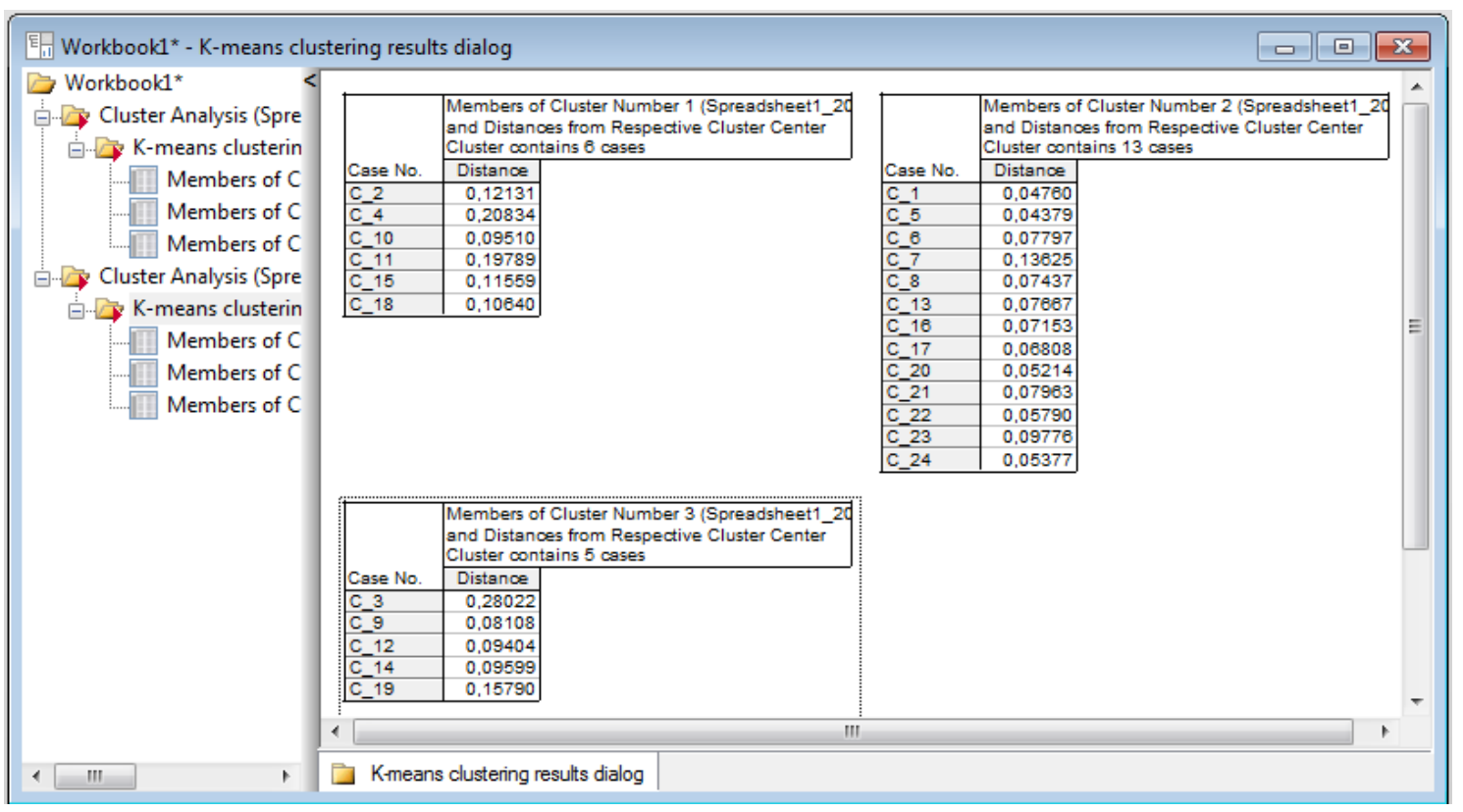

Figure 1. Results of the Clustering of Ukraine's regions by the economic development indicators 
Figure analysis allows to make a conclusion that clustering results showed reasonable agreement with outcomes obtained by the means of comprehensive index. First cluster by the content is equal to the third group of Ukraine's regions, second cluster corresponds to second group and third cluster corresponds to first group. We have only difference for Poltava and Donetsk regions. By the value of comprehensive indicator, they were allocated to the second group with an average level of economic development, but on the results of clustering these regions were included to the cluster with a level of economic development below the average value. In our opinion, it can be explained by rather low values of relative indicators of economic development for Poltava and Donetsk regions. According to indicators measured in absolute scale, these regions have values close to the average value. We note, when classifying regions by the value of the comprehensive index there are significant differences between some regions in the first and third groups. In particular, for the object C_ 9 (Kyiv region) of the first group of regions, the value of the indicator $\delta_{j}$ is 0.89 , that is equal to the limit value that we have chosen for grouping regions. A similar situation exists for the C_2 object (Volyn region) of the third group of regions.

So, in this case, it is possible to propose the allocation of regions into new five groups. The first and second as well as the fourth and fifth new groups will be formed by dividing the previous first and third groups respectively. At the same time, the first group can be interpreted as regions with a relatively high level of economic development, it will contain only Dnipro region, and the fifth group, which consist of Volyn region and Luhansk region, can be interpreted as regions with a relatively low level of economic development. The other three groups will have a previous interpretation.

Further we execute similar calculations according to 2016 data. Initial values of indicators are shown in the Table 4, normalized values - in the Table 5, and ranked regions and corresponding them values of comprehensive index of economic development - in the Table 6.

Table 4. Values of the initial indicators for 2016

\begin{tabular}{clccccccc}
\hline Code & \multicolumn{1}{c}{ Region } & $X_{1}$ & $X_{2}$ & $X_{3}$ & $X_{4}$ & $X_{5}$ & $X_{6}$ & $X_{7}$ \\
\hline C_1 & Vinnytsia & 8302 & 983.0 & 56.6 & 9.7 & 106.5 & 105.3 & 117.0 \\
C_2 & Volyn & 6384 & 611.9 & 51.0 & 11.5 & 108.2 & 100.2 & 101.9 \\
C_3 & Dnipro & 33169 & 5864.8 & 59.1 & 7.9 & 98.4 & 99.3 & 100.3 \\
C_4 & Donetsk & 11902 & 3430.8 & 50.0 & 14.1 & 99.1 & 106.4 & 108.3 \\
C_5 & Zhytomyr & 5573 & 484.7 & 55.9 & 11.2 & 105.2 & 105.7 & 116.7 \\
C_6 & Zakarpattia & 4663 & 1211.9 & 54.8 & 10.0 & 97.3 & 105.9 & 96.8 \\
C_7 & Zaporizhzhia & 11040 & 2292.8 & 56.0 & 10.0 & 99.7 & 96.9 & 98.7 \\
C_8 & Ivano-Frankivsk & 7948 & 573.7 & 54.7 & 8.8 & 99.0 & 95.5 & 101.7 \\
C_9 & Kyiv & 33411 & 1705.1 & 57.8 & 6.8 & 105.7 & 106.2 & 109.8 \\
C_10 & Kyrovohrad & 6355 & 427.4 & 52.9 & 12.4 & 105.0 & 120.3 & 109.4 \\
C_11 & Luhansk & 4122 & 435.7 & 55.6 & 16.0 & 118.0 & 139.0 & 119.3 \\
C_12 & Lviv & 18605 & 1275.6 & 55.9 & 7.7 & 99.3 & 99.3 & 102.6 \\
C_13 & Mykolaiv & 9730 & 1666.4 & 57.5 & 9.7 & 105.6 & 110.5 & 108.5 \\
C_14 & Odesa & 16729 & 1520.5 & 56.7 & 6.8 & 104.2 & 109.2 & 111.6 \\
C_15 & Poltava & 15265 & 1436.0 & 53.3 & 12.6 & 97.9 & 100.1 & 103.3 \\
C_16 & Rivne & 4324 & 318.3 & 56.9 & 10.6 & 100.3 & 98.1 & 104.9 \\
C_17 & Sumy & 5763 & 542.2 & 56.8 & 9.3 & 96.6 & 91.2 & 103.5 \\
C_18 & Ternopil & 4888 & 294.3 & 52.0 & 11.5 & 98.5 & 110.3 & 104.6 \\
C_19 & Kharkiv & 16546 & 1027.8 & 59.7 & 6.4 & 102.1 & 105.8 & 106.6 \\
C_20 & Kherson & 4591 & 246.6 & 55.8 & 11.2 & 102.8 & 102.0 & 103.7 \\
C_21 & Khmelnytskyi & 9123 & 318.7 & 53.9 & 9.4 & 104.7 & 104.7 & 108.2 \\
C_22 & Cherkasy & 6499 & 474.3 & 56.2 & 10.4 & 101.8 & 106.3 & 102.5 \\
C_23 & Chernivtsi & 2669 & 119.3 & 56.2 & 8.7 & 99.4 & 96.9 & 100.0 \\
C_24 & Chernihiv & 5319 & 432.8 & 55.6 & 11.3 & 100.6 & 105.8 & 104.5 \\
\hline & & & & & & & & \\
\hline
\end{tabular}


Table 5. Normalized values of indicators for 2016

\begin{tabular}{cccccccc}
\hline Code & $U_{1}$ & $U_{2}$ & $U_{3}$ & $U_{4}$ & $U_{5}$ & $U_{6}$ & $U_{7}$ \\
\hline C_1 & 0.22 & 0.15 & 0.55 & 0.56 & 0.93 & 0.96 & 0.86 \\
C_2 & 0.10 & 0.08 & 0.00 & 0.39 & 0.95 & 0.94 & 0.94 \\
C_3 & 1.00 & 1.00 & 0.78 & 0.77 & 0.95 & 0.89 & 0.90 \\
C_4 & 0.36 & 0.62 & 0.05 & 0.19 & 0.85 & 0.79 & 0.91 \\
C_5 & 0.12 & 0.06 & 0.64 & 0.55 & 0.94 & 0.98 & 0.94 \\
C_6 & 0.07 & 0.19 & 0.42 & 0.58 & 0.91 & 0.89 & 0.91 \\
C_7 & 0.32 & 0.41 & 0.54 & 0.56 & 0.96 & 0.95 & 0.86 \\
C_8 & 0.17 & 0.07 & 0.53 & 0.77 & 0.98 & 1.00 & 0.93 \\
C_9 & 0.79 & 0.23 & 0.78 & 0.96 & 0.97 & 0.98 & 0.85 \\
C_10 & 0.11 & 0.04 & 0.38 & 0.42 & 0.87 & 0.94 & 0.77 \\
C_11 & 0.01 & 0.01 & 0.50 & 0.00 & 0.79 & 0.61 & 0.84 \\
C_12 & 0.53 & 0.21 & 0.63 & 0.87 & 0.93 & 0.94 & 0.95 \\
C_13 & 0.21 & 0.25 & 0.68 & 0.60 & 0.90 & 0.90 & 0.81 \\
C_14 & 0.48 & 0.24 & 0.62 & 0.89 & 0.98 & 1.00 & 0.89 \\
C_15 & 0.32 & 0.25 & 0.44 & 0.44 & 0.88 & 0.88 & 0.74 \\
C_16 & 0.08 & 0.03 & 0.53 & 0.48 & 0.92 & 0.97 & 0.94 \\
C_17 & 0.10 & 0.08 & 0.73 & 0.71 & 0.95 & 0.91 & 0.89 \\
C_18 & 0.10 & 0.03 & 0.19 & 0.45 & 0.95 & 0.97 & 0.99 \\
C_19 & 0.41 & 0.15 & 1.00 & 1.00 & 0.92 & 0.95 & 0.80 \\
C_20 & 0.11 & 0.02 & 0.63 & 0.52 & 0.92 & 0.92 & 0.89 \\
C_21 & 0.19 & 0.05 & 0.50 & 0.73 & 1.00 & 0.91 & 1.00 \\
C_22 & 0.13 & 0.07 & 0.67 & 0.61 & 0.90 & 0.88 & 0.79 \\
C_23 & 0.00 & 0.00 & 0.66 & 0.78 & 0.92 & 0.95 & 0.94 \\
C_24 & 0.11 & 0.07 & 0.62 & 0.51 & 0.91 & 0.86 & 0.94 \\
\hline & & & & & & &
\end{tabular}

Analysis results of Table 6 shows that it is appropriate to categorize the Dnipro, Kyiv, Kharkiv and Odesa regions to the first group of regions with a level of economic development above the average value. In this case, Lviv region should be classified to the second group. This is evidenced both by the value of the coefficient $\delta$ and the value of the comprehensive index of economic development for this region.

Comparison of the value of the comprehensive index for 2016 for the Lviv region with the comprehensive index values for the regions included in the second group according to the data of 2017 also testifies to the correctness of such grouping. However, the results of cluster analysis show that the Lviv region should be classified into the cluster with a level of economic development above the average (see Fig. 2).

In our view, grouping by comprehensive index is more correct. This is indicated by the analysis of the normalized values of the initial indicators in 2016 for this region, which are below the corresponding values in 2017. The allocation of the remaining regions by the values of the comprehensive index for data 2016 between the second and third groups is the same as that for 2017 data. The clustering results of these regions also coincide with those ones obtained in the previous case for data 2017.

Consequently, the calculations results show that for both sets of data, the outcomes of grouping according to the values of the comprehensive index have practically identical appearance, which indicates the absence of significant shifts in the pattern of Ukraine's regions by the level of economic development. This finding is also evidenced by the clustering outcomes. 
Table 6. Ranking of the Ukraine's regions by the values of the comprehensive index for 2016 data

\begin{tabular}{clccc}
\hline Code & \multicolumn{1}{c}{ Region } & $Q$ & Region's rank & $\delta$ \\
\hline C_3 & Dnipro & 0.866 & 1 & - \\
C_9 & Kyiv & 0.807 & 2 & 0.93 \\
C_19 & Kharkiv & 0.739 & 3 & 0.92 \\
C_14 & Odesa & 0.713 & 4 & 0.96 \\
C_12 & Lviv & 0.663 & 5 & 0.93 \\
C_13 & Mykolaiv & 0.646 & 6 & 0.97 \\
C_7 & Zaporizhzhia & 0.610 & 7 & 0.95 \\
C_1 & Vinnytsia & 0.605 & 8 & 0.99 \\
C_17 & Sumy & 0.552 & 9 & 0.91 \\
C_8 & Ivano-Frankivsk & 0.541 & 10 & 0.98 \\
C_22 & Cherkassy & 0.540 & 11 & 1.00 \\
C_21 & Khmelnytskyi & 0.531 & 12 & 0.98 \\
C_23 & Chernivtsi & 0.526 & 13 & 0.99 \\
C_5 & Zhytomyr & 0.525 & 14 & 1.00 \\
C_16 & Rivne & 0.525 & 15 & 1.00 \\
C_6 & Zakarpattia & 0.524 & 16 & 1.00 \\
C_15 & Poltava & 0.517 & 17 & 0.99 \\
C_24 & Chernihiv & 0.500 & 18 & 0.97 \\
C_20 & Kherson & 0.493 & 19 & 0.99 \\
C_4 & Donetsk & 0.474 & 20 & 0.96 \\
C_10 & Kyrovohrad & 0.434 & 21 & 0.92 \\
C_11 & Luhansk & 0.412 & 22 & 0.95 \\
C_18 & Ternopil & 0.403 & 23 & 0.98 \\
C_2 & Volyn & 0.401 & & 1.00 \\
\hline & & & 24 & \\
\hline
\end{tabular}

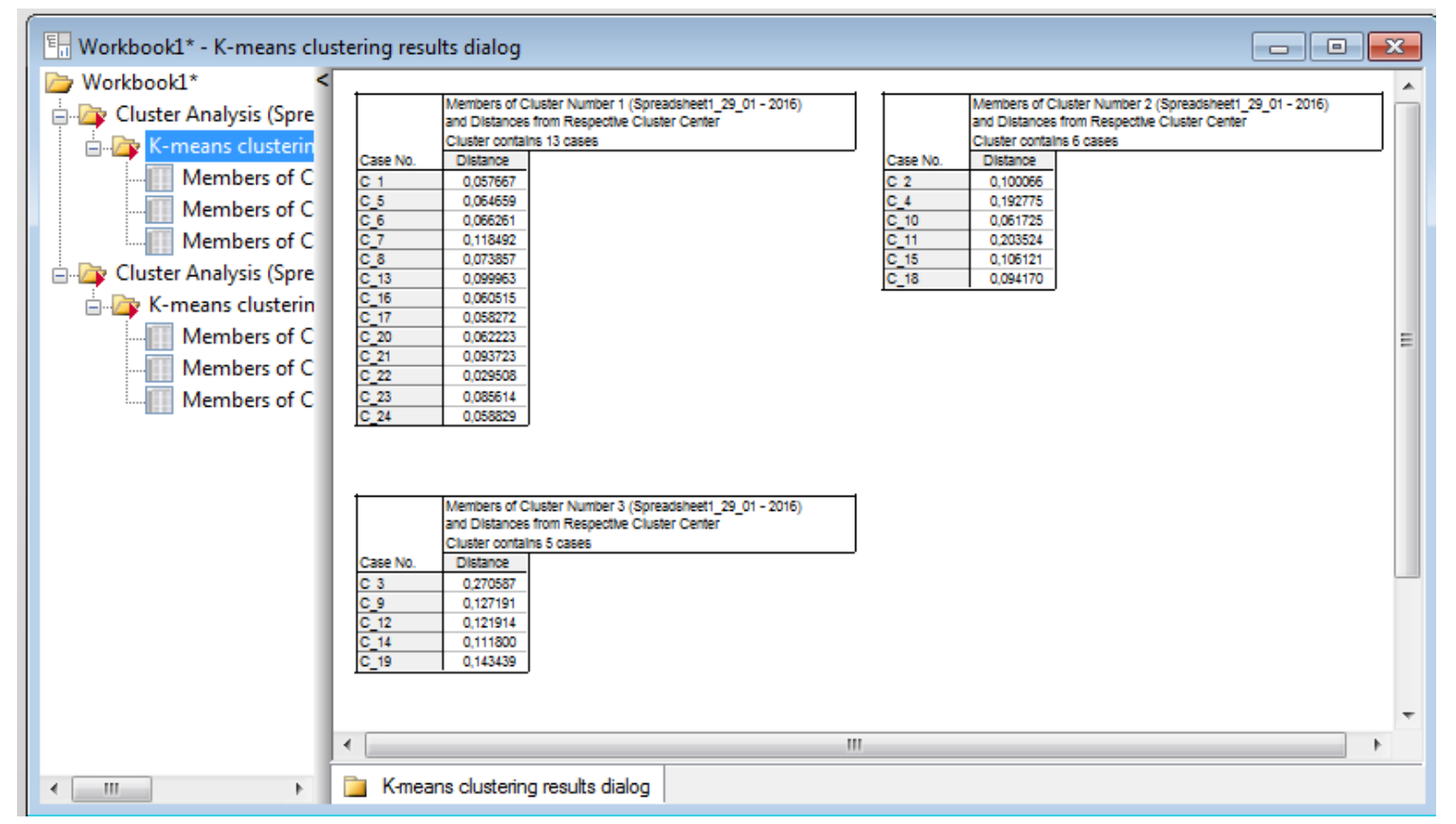

Figure 2. Results of the Clustering of Ukraine's regions by the economic development indicators for 2016 data 


\section{Conclusion}

In this study, a model of comprehensive assessment of the economic development level of regions was developed for the purpose of rating them. The various origins of the initial indicators and the different direction of their positive influence on the level of economic development can be taken into account by grouping them with similar characteristics, different ways of normalizing the data of each group and choosing the aggregation function of convolution. The number of indicators in each group is selected by the researcher, but their excessive number can reduce the impact of each component on the final result. The calculated comprehensive indicator can be used to allocate the regions into groups with similar levels of economic development. Proposed approach is implemented for Ukraine as developing economy. This study uses an allocation of regions into three groups. The results of grouping the regions of Ukraine by the value of the comprehensive index almost coincide with the results of clustering on the same data. This approach shows that grouping can be done for a different number of groups. Unlike cluster analysis, we can see not only the results of grouping, but also the differences in the development of regions both in the inside of each group and between groups. The proposed approach to assessing the level of economic development of regions can also be used to study the disproportions in the development of regions and structural changes in their development over time. Areas for further research are to identify and justify the intervals' bounds of comprehensive index for each selected group and create on this base the scale of regions' economic development. It will allow to group regions by the obtained scale for the next periods data.

\section{Acknowledgements}

This study was supported by State budget project of Khmelnytskyi National University, project's registration number 0117 U001170.

[1] State Strategy of Regional Development for the period up to 2020 [cited 2019 January 15]. Available from: http://zakon3.rada.gov.ua/laws/show/385-2014-\%D0\%BF\#n11.

[2] M. Tvrdon, "Cohesion, Convergence and Regional Disparities: The case of European Union", WSEAS. Transactions on Business and Economics, vol. 9 (2), pp. 89-99, 2012.

[3] P. P. Sengupta, M. Sinha and U. P. Dutta, "Economic and environmental performances in manufacturing industries: A comparative study", Periodicals of Engineering and Natural Sciences (PEN), vol. 7-1, pp. 99-108, 2019.

[4] Y. S. Gultekin, P. Gultekin, O. Uzun and H. Gok, "Use of Structural Equation Modeling in Ecotourism: A Model Proposal”, Periodicals of Engineering and Natural Sciences (PEN), vol. 5-2, pp. 145-151, 2017.

[5] Tb. Ai. Munandar, R. Wardoyo, "Fuzzy-Klassen Model for Development Disparities Analysis based on Gross Regional Domestic Product Sector of a Region", International Journal of Computer Applications, vol.123 (7), pp. 17-22, 2015.

[6] Tb. Ai Munandar, Azhari, A. Musdholifah and L. Arsyad, "Multiview Hierarchical Agglomerative Clustering for Identification of Development Gap and Regional Potential Sector", Journal of Computer Science, vol. 14 (1), pp. 81-91, 2018.

[7] H. V. Azarova, "Integral Evaluation of the Level of Socio-Economic Development of Ukraine's Regions", Economics and Law. Series "Economics", vol. 1, pp. 61-65, 2015. (in Ukrainian).

[8] V. Babenko, M. Pasmor, Ju. Pankova and M. Sidorov, "The place and perspectives of Ukraine in international integration space", Problems and Perspectives in Management, vol. 15 (1), pp. 80-92, 2017.

[9] Ye. Dertishnikova, "Complex Evaluation of Socio-Economic Development of Region", Problems of Territory's Development, vol. 1, pp. 25-35, 2011. (in Russian).

[10] O. A. Geyman and O. M. Krupa, "Analysis of Irregularity of Economic Development of the Regions of Ukraine", The problems of economy, vol. 4, pp. 37-45, 2009. (in Ukrainian).

[11] I. Parshyn, "Integral Assessment of the Regional Economic Development Efficiency", Economics of development, vol. 1, pp. 27-33, 2014. (in Ukrainian).

[12] E. Poledníkova, "Comparing regions' ranking by MCDM methods: the case of visegrad countries", WSEAS Transactions on Business and Economics, vol. 11(1), pp. 496-507, 2014 
[13] E. Poledníkova and L. Melecky, "Weighting methods for constructing composite indices in regional development", 11th International Days of Statistics and Economics: conference proceedings, pp. 12531252, 2017.

[14] U. S. Savkiv, "Integral Estimates of Sustainable Development of the Region", Business Inform, vol. 1, pp. 45-50, 2012. (in Ukrainian).

[15] R. A. Flarence, S. Bethu, V. Sowmya, K. Anusha and B. S. Babu, "Importance of Supervised Learning in Prediction Analysis", Periodicals of Engineering and Natural Sciences (PEN), vol.6-1, pp. 201-214, 2018.

[16] V. I. Lapshyn, "Socio-Economic State of Regions of Ukraine: Rating, Clusters", Eastern Europe, Economics, Business and Management, vol. 3, pp. 215-219, 2017. (in Ukrainian).

[17] Tb. Ai Munandar, "Analysis of Regional Development Disparity with Clustering Technique Based Perspective", International Journal of Advanced Research in Computer Science, vol. 6 (1), pp. 137-141, 2015.

[18] M. Staníckova and L. Melecky, "Multidimensional Approach to Evaluation of Visegrad Countries'Competitiveness in Comparison with Austria and Germany", Journal of Competitiveness, vol. 4 (3), pp. 58-76, 2012.

[19] K. N. Zivadinovic, K. Dumicic and C. A. Casni, "Cluster and Factor Analysis of Structural Economic Indicators for Selected European Countries", WSEAS Transactions on Business and Economics, vol. 6 (7), pp. 331-341, 2009.

[20] E. Minarcíkova, "Evaluation of Regional Disparities in Visegrad Four based on Selected MCDM Methods", 9th International Days of Statistics and Economics, pp. 1128-1137, 2015.

[21] N. Ye. Seliuchenko, "Evaluation of Ukrainian Regions by Conditions for the Development of Creative Sector of Economy", Effective Economy, vol. 4, 2016. [cited 2019 January 15]. Available from: http://www.economy.nayka.com.ua/?op=1\&z=4896 (in Ukrainian).

[22] I. E.Verner, (ed), Statistical Yearbook of Ukraine for 2017. Kyiv:State Statistics Service of Ukraine, 2018. (in Ukrainian).

[23] State Statistics Service of Ukraine [cited 2019 January 21]. Available from: http://www.ukrstat.gov.ua/ 